\title{
EFEKTIVITAS STROKE EDUCATION PROGRAM ( SEP) TERHADAP PERAN FAMILY CAREGIVER DALAM MODIFIKASI GAYA HIDUP PASIEN POST STROKE: A LITERATURE REVIEW
}

\author{
Effectiveness Of Stroke Education Program (Sep) On \\ The Role Of Family Caregiver In Modification Of Life \\ Style Post Life Style): A Literature Review
}

Yeni Isnaeni $^{1,}$ Kusbaryanto $^{2}$

Master of Nursing Faculty of Medicine and Health Sciences ${ }^{1}$, Lecture Master of Nursing Faculty of Medicine and Health Sciences ${ }^{2}$ University of Muhammadiyah

Yogyakarta, Ring Road Selatan, Bantul, Yogyakarta

(yeniisnaeni09@gmail.com)

\begin{abstract}
ABSTRAK
Latar Belakang: Stroke Education Program merupakan program edukasi yang melibatkan pasien dan keluarga sebagai caregiver informal yang diberikan ketika pasien dirawat dan setelah pulang ke rumah.

Tujuan Penelitian: Menganalisis Efektivitas Stroke Education Program terhadap Peran family caregiver dalam modifikasi gaya hidup pasien post stroke, agar tidak terjadi stroke berulang.

Metode: Literature Review, Pencarian artikel dimulai tanggal 1-7 desember 2017 melalui database Proquest, Pubmed dan Science Direct yang menggunakan kata kunci stroke AND efektivitas education program AND Post Stroke, kemudian pemilihan berdasarkan kriteria inklusi dilakukan critical appraisal sehingga artikel yang relevant berjumlah 10 artikel..

Hasil: Pada tahun 2012, sekitar 50.000 orang mengalami stroke (Allan et al, 2014). risiko stroke berulang dipengaruhi oleh diagnostik, diet, dan gaya hidup (Wein et al,2017). Risiko stroke berulang selanjutnya ditambah dengan peningkatan tekanan darah. Meta-analisis RCTs telah melaporkan adanya penurunan sampai dengan 30\%-40\% risiko stroke berulang dengan terapi penurun tekanan darah (Boan et al, 2014). Pasien dengan diagnosis stroke, kemungkinan akan kembali ke rumah dengan cacat sisa dan dengan pengasuh yang memberikan dukungan yang memenuhi syarat (Forster et al, 2013).

Kesimpulan: Stroke Education Program efektif untuk meningkatkan peran family caregiver dalam modifikasi gaya hidup pasien post stroke.
\end{abstract}

Kata kunci: Stroke education program, peran family caregiver, Pasien post stroke

\section{ABSTRACT}

Background: Stroke Education Program is an educational program involving patients and families as an informal caregiver given when patients are treated and after returninghome.

Efektivitas Stroke Education Program ( Sep) Terhadap Peran Family Caregiver Dalam Modifikasi Gaya Hidup Pasien Post Stroke: A Literature Review

(Yeni Isnaeni, Kusbaryanto) 
Objective: Analyzing the Effectiveness of Stroke Education Program on the role of family caregiver in the lifestyle modification of post stroke patients, in order to avoid recurrent stroke.

Methods: Literature Review The article search begins on 1-7 December 2017 through Proquest, Pubmed and Science Direct databases using keyword strokes AND education effectiveness of the program AND Post Stroke, then selection based on inclusion criteria conducted critical appraisal so that the relevant articles amounted to 10 articles .and 693. Of the overall database ProQuest only 11 met inclusion criteria.

Result: In 2012, about 50,000 people had a stroke (Allan et al, 2014). The risk of recurrent stroke is affected by diagnostics, diet, and lifestyle (Wein et al, 2017). The risk of recurrent stroke is further coupled with an increase in blood pressure. Meta-analysis of RCTs has reported a decrease of up to 30\% $-40 \%$ risk of recurrent stroke with blood pressure-lowering therapy (Boan et al, 2014). Patients with a stroke diagnosis, likely to return home with residual defects and with caregivers who provide eligible support (Forster et al, 2013).

Conclusion: Stroke Education Program is effective to increase the role of family caregiver in the modification of post-stroke patient lifestyle.

Keyword: Stroke education program, family caregiver role, Patient post stroke.

\section{PENDAHULUAN}

Stroke adalah masalah kesehatan masyarakat yang penting di seluruh dunia. Setiap tahun, sekitar 5,5 juta orang meninggal karena stroke, dan 44 juta orang mengalami kehilangan kemampuan secara fisik (Pitthayapong et al., 2017). Faktor resiko terjadinya stroke adalah diabetes, hiperlipidemia, fibrilasi atrium, dan hipertensi serta merokok ( Bushnell et all., 2014). Ketergantungan dan beban substansial ditempatkan secara informal oleh caregiver, biasanya anggota keluarga untuk memberikan bantuan pada aktivitas sehari-hari, dari berpakaian, toileting setelah perawatan di rumah sakit. Intervensi yang efektif diarahkan pada caregiver untuk memperbaiki pemulihan dan penyesuaian pasien yang mengalami stroke. Program pelatihan yang sistematis dan terstruktur untuk caregiver sangat penting untuk pengelolaan sehari-hari pasien stroke yang mengalami disfungsi (Forster et al., 2013 ).

Dengan melihat kejadian stroke diatas, sehingga dilakukan kajian literature yang mendalam terhadap bagaimana memberikan education terhadap family sebagai caregiver dalam modifikasi gaya hidup pada pasien post stroke agar tidak terjadi stroke berulang.

\section{METODE PENELITIAN}

Pencarian artikel dimulai tanggal 1-7 desember 2017 melalui database Proquest, Pubmed dan Science Direct yang menggunakan kata kunci stroke AND efektivitas education program AND Post Stroke, kemudian pemilihan berdasarkan

Efektivitas Stroke Education Program ( Sep) Terhadap Peran Family Caregiver Dalam Modifikasi Gaya Hidup Pasien Post Stroke: A Literature Review 
kriteria inklusi dilakukan critical appraisal sehingga artikel yang relevant berjumlah 10 artikel (tabel 1). Setelah melakukan proses pemilihan artikel dengan kriteria yang sesuai sehingga hasil artikel yang berdasarkan kriteria inklusi berjumlah 217 artikel, kemudian melakukan critical appraisal menggunakan format Joanna Briggs Institute (JBI) dari 217 artikel yang di dilakukan critical appraisal dan didapatkan hasil keseluruhan artikel yang relevant dan dapat dilakukan literature review sebanyak 10 artikel.

\section{Criteria}

Tabel 1. Daftar kriteria artikel untuk dilakukan literature review

\begin{tabular}{ll}
\hline \multicolumn{1}{c}{ Inklusi } & \multicolumn{1}{c}{ Eksklusi } \\
\hline $\begin{array}{l}\text { Penelitian harus ada kaitannya dengan } \\
\text { edukasi }\end{array}$ & $\begin{array}{l}\text { Publikasi hanya sebagai surat ke editor, } \\
\text { abstrak saja dan editorial }\end{array}$ \\
\hline $\begin{array}{l}\text { Penelitian harus berkaitan dengan pasien } \\
\text { post stroke }\end{array}$ & \\
\hline Teks lengkap bahasa inggris & \\
\hline
\end{tabular}

\section{HASIL DAN PEMBAHASAN}

Kajian artikel di identifikasi dari 10 artikel yang sudah dilakukan dengan langkah-langkar kritis sehingga dapat dilihat bahwa dari 10 artikel membahas tentang edukasi pada family caregiver pasien post stroke.

Tabel 2. Studies included in the literature review 


\begin{tabular}{|c|c|c|c|c|}
\hline $\begin{array}{l}\text { Author } \\
\text { (Year ) }\end{array}$ & Purpose & $\begin{array}{l}\text { Study } \\
\text { design }\end{array}$ & Sample & Relevant \\
\hline $\begin{array}{l}\text { Pitthayapo } \\
\text { ng et al } \\
(2017)\end{array}$ & $\begin{array}{l}\text { Tujuan dari } \\
\text { penelitian ini } \\
\text { adalah untuk } \\
\text { mengevaluasi } \\
\text { efektivitas } \\
\text { program } \\
\text { perawatan } \\
\text { pasca stroke } \\
\text { dalam } \\
\text { lingkungan } \\
\text { komunitas di } \\
\text { Thailand. }\end{array}$ & $\begin{array}{l}\text { Metode: } \\
\text { Penelitian } \\
\text { kuasi- } \\
\text { eksperiment } \\
\text { al }\end{array}$ & $\begin{array}{lr}\text { kelompok pre-test } \\
\text { dan post test yang } \\
\text { tidak } & \text { ada } \\
\text { hubungannya } \\
\text { Desain. Sebanyak } \\
62 \text { pasang pasien } \\
\text { pasca stroke dan } \\
\text { family } \\
\text { caregiver,mereka } \\
\text { direkrut untuk } \\
\text { di edukasi } \\
\text { pasang } 31 \\
\text { kelompok) }\end{array}$ & 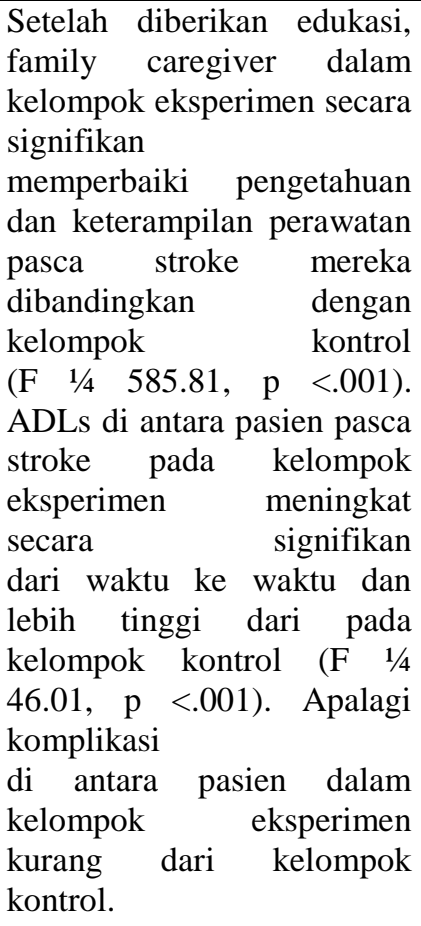 \\
\hline $\begin{array}{l}\text { Bushnell } \\
\text { et al } \\
(2014)\end{array}$ & $\begin{array}{l}\text { Tujuan dari } \\
\text { penelitian ini } \\
\text { adalah } \\
\text { Mencegah } \\
\text { terulangnya } \\
\text { kejadian } \\
\text { tromboemboli } \\
\text { melalui } \\
\text { Program } \\
\text { perawatan } \\
\text { terkoordinasi } \\
\text { (PROTECT) } \\
\text { adalah kualitas } \\
\text { program } \\
\text { perbaikan } \\
\text { yang } \\
\text { dirancang } \\
\text { untuk } \\
\text { meningkatkan } \\
\text { kepatuhan } \\
\text { dengan } \\
\text { medications } \\
\text { dan perubahan } \\
\text { perilaku } \\
\text { setelah stroke } \\
\text { dan koroner } \\
\text { akut } \\
\text { sindrom arteri }\end{array}$ & $\begin{array}{l}\text { A randomie } \\
\text { clinical } \\
\text { study design }\end{array}$ & $\begin{array}{l}\text { Dari } 171 \text { pasien } \\
\text { yang terdaftar, } 15 \\
\text { pasien dipulangkan } \\
\text { ke fasilitas } \\
\text { keperawatan yang } \\
\text { terampil atau } \\
\text { fasilitas rehabilitasi } \\
\text { rawat inap di luar, } \\
\text { dan } 14 \text { pasien } \\
(8,2 \%) \text { hilang untuk } \\
\text { follow up, Sebanyak } \\
142 \\
\text { pasien dimasukkan } \\
\text { dalam analisis ini }\end{array}$ & $\begin{array}{l}\text { Kegigihan lebih tinggi pada } \\
\text { pasien } \\
\text { stroke pertama }(78,9 \%) \\
\text { dibandingkan dengan stroke } \\
\text { berulang }(60,7 \% \text {; } \\
\text { p = 0,045), sedangkan tidak } \\
\text { ada faktor lain yang terkait } \\
\text { dengannya } \\
\text { kegigihan. } \\
\text { Pemodelan regresi logistik } \\
\text { multivariat menunjukkan } \\
\text { sebelumnya ka } \\
\text { stroke / TIA dikaitkan secara } \\
\text { negatif dengan ketekunan } \\
\text { (OR } 0,21, \\
\text { 95\% CI 0,06-0,72; p = } \\
\text { 0,013) setelah penyesuaian } \\
\text { untuk usia, jenis kelamin, } \\
\text { ras, } \\
\text { pendidikan, asuransi, dan } \\
\text { kunjungan kantor setelah } \\
\text { diberhentikan }\end{array}$ \\
\hline $\begin{array}{l}\text { Forster et } \\
\text { al } \\
\text { Efektivitas } \\
\text { Modifikasi } \\
\text { (Yeni Isnae }\end{array}$ & $\begin{array}{l}\text { Sebagian } \\
\text { besar pasien } \\
\text { Stroke Educatic } \\
\text { Gaya Hidup Pa } \\
\text { ni, Kusbaryant }\end{array}$ & controlled & $\begin{array}{l}\text { Terdapat } 49 \text { pasien } \\
\text { stroke } 4 \text { untuk } \\
\text { ep) Terhadap Peran } \\
\text { e: } \boldsymbol{A} \text { Literature } \text { Revi }\end{array}$ & $\begin{array}{l}\text { Dalam skala besar, evaluasi } \\
\text { yang kuat, hasil dari } \\
\text { Family } \text { Caregiver Dalam }\end{array}$ \\
\hline
\end{tabular}




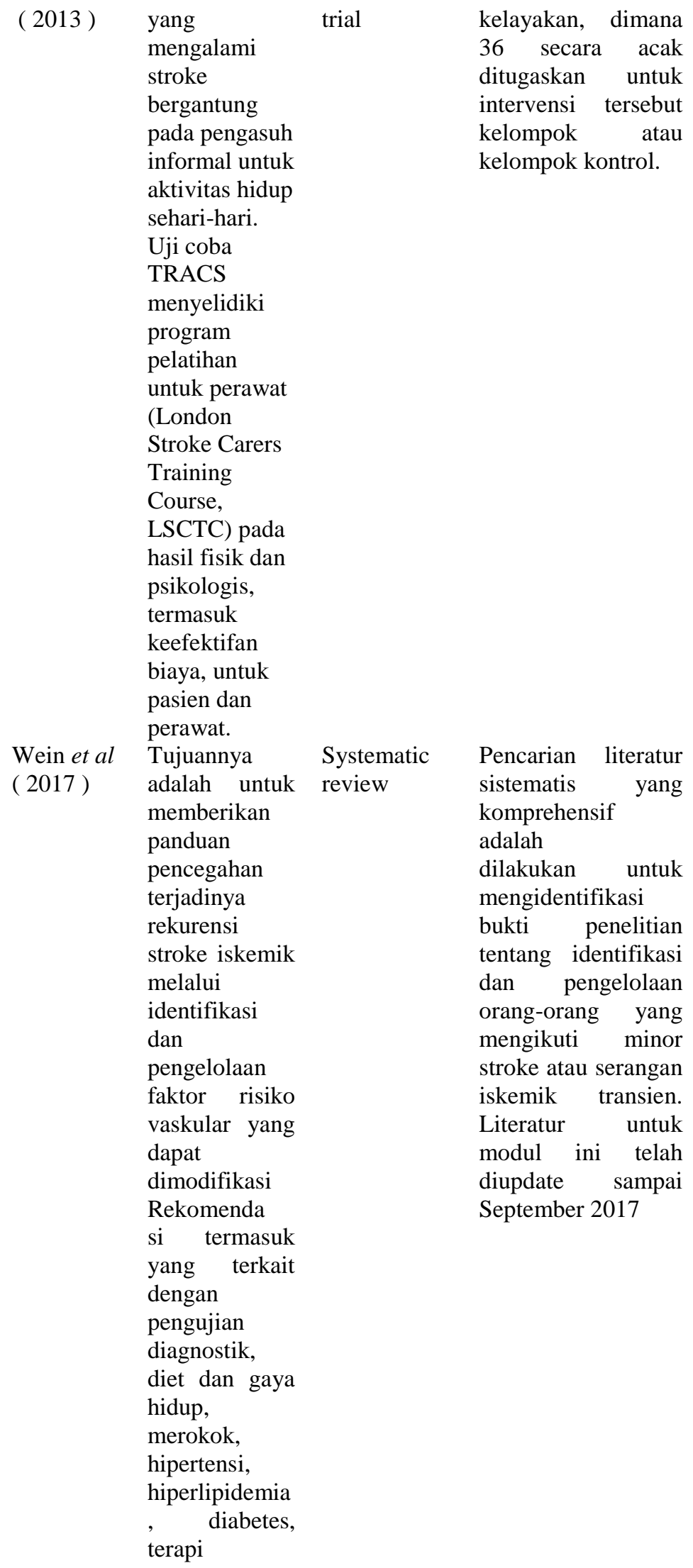

penelitian ini tidak menunjukkan adanya perbedaan antara LSCTC dan perawatan biasa pada hasil yang dinilai. Periode segera setelah stroke mungkin tidak ideal waktu untuk memberikan pelatihan perawat terstruktur

Efektivitas Stroke Education Program ( Sep) Terhadap Peran Family Caregiver Dalam Modifikasi Gaya Hidup Pasien Post Stroke: A Literature Review 


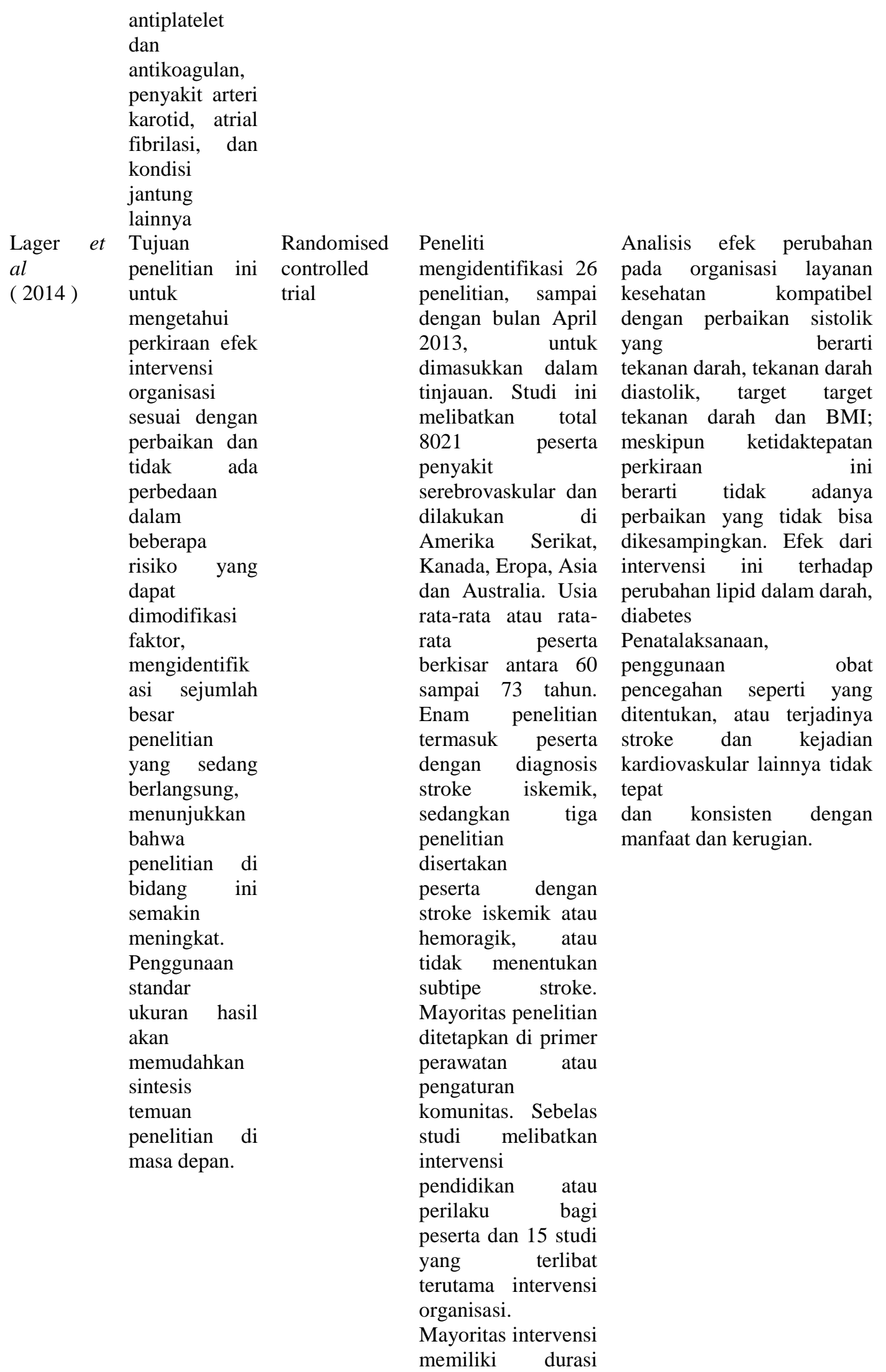




\begin{tabular}{|c|c|c|}
\hline $\begin{array}{l}\text { Gong et al } \\
\text { ( 2015) }\end{array}$ & $\begin{array}{l}\text { Mengevaluasi } \\
\text { kemanjuran } \\
\text { program } \\
\text { Jauhkan } \\
\text { Bergerak } \\
\text { menuju } \\
\text { Jantung Sehat } \\
\text { dan Sehat } \\
\text { Otak (KM2H2 } \\
\text { ) dalam } \\
\text { mendorong } \\
\text { aktivitas fisik } \\
\text { untuk } \\
\text { pencegahan } \\
\text { serangan } \\
\text { jantung dan } \\
\text { stroke antara } \\
\text { pasien } \\
\text { hipertensi } \\
\text { yang terdaftar } \\
\text { dalam } \\
\text { Hipertensi } \\
\text { Berbasis } \\
\text { Komunitas } \\
\text { Con- } \\
\text { Program trol } \\
\text { (CBHCP }\end{array}$ & $\begin{array}{l}\text { Randomised } \\
\text { controlled } \\
\text { trial }\end{array}$ \\
\hline $\begin{array}{l}\text { Stewart et } \\
\text { al } \\
(2016)\end{array}$ & $\begin{array}{l}\text { Studi ini } \\
\text { menilai sejauh } \\
\text { mana orang } \\
\text { dewasa yang } \\
\text { lebih tua } \\
\text { mengaitkan } \\
\text { serangan } \\
\text { jantung } \\
\text { stroke baru- } \\
\text { baru ini } \\
\text { menjadi "usia } \\
\text { tua," dan } \\
\text { memeriksa } \\
\text { konsekuensi } \\
\text { untuk perilaku } \\
\text { gaya hidup } \\
\text { selanjutnya } \\
\text { dan pemanfaatan } \\
\text { pemanan } \\
\text { layanan } \\
\text { perawatan } \\
\text { kesehatan. }\end{array}$ & $\begin{array}{l}\text { Randomised } \\
\text { controlled } \\
\text { trial }\end{array}$ \\
\hline
\end{tabular}

antara tiga dan 12

bulan.

Sebanyak $\quad 450$ peserta didiagnosis menderita hipertensi dari 12 puskesmas di Wuhan, Cina direkrut, dan ditugaskan secara acak oleh pusat untuk menerima keduanya

KM2H2 ditambah perawatan standar CBHCP (6 pusat dan 232 pasien) atau perawatan standar saja

(6 pusat dan 218 pasien)
Serangan jantung dan stroke (didiagnosis secara klinis, hasil primer), tekanan darah (diukur,

hasil sekunder), dan aktivitas fisik (self-report, tersier) dinilai di tingkat individu selama baseline, intervensi pasca-3 dan 6 bulan.

\section{Orang dewasa yang tinggal $(\mathrm{N}=57$, usia 73-98 tahun) diwawancarai tentang serangan / stroke jantung. peserta yang bertemu dengan crite- \\ ria: (a) berada di salah satu provinsi kota, (b) tinggal di masyarakat (vs pribadi} perawatan rumah), (c) memiliki tingkat memuaskan pemahaman, dan (d) memahami dalam bahasa Inggris. Selain itu, untuk dimasukkan dalam analisis saat ini, peserta harus mengalami serangan jantung
Regresi digunakan untuk menguji hubungan antara menghubungkan serangan jantung / stroke dengan "Usia tua" dan tiga variabel dependen.

Model regresi linier terpisah digunakan untuk dua variabel dependen terus menerus (perubahan perilaku gaya hidup dan kunjungan dokter), dan regresi logistik digunakan untuk dichotovariabel rawat inap mull (Pampel, 2000). Semua model termasuk usia, jenis kelamin, dan tingkat keparahan

kondisi kronis seperti kovariat. Satu-ekor nilai $\mathrm{t}$ kritis diadopsi mengingat direchipotesis nasional bahwa atribusi usia tua akan dikaitkan dengan hasil 


$\begin{array}{ll}\text { Song et al } & \text { Tujuan dari } \\ \text { (2014) } & \text { penelitian ini } \\ & \text { adalah untuk } \\ \text { mengevaluasi } & \text { keefektifan } \\ \text { intervensi } & \text { berbasis } \\ \text { masyarakat } & \text { untuk } \\ & \text { orang dewasa } \\ \text { prehypertensiv } & \text { e } \\ \text { meningkatkan } \\ \text { kesadaran } \\ \text { akan risiko } \\ \text { stroke dan } \\ \text { menerapkan } \\ \text { gaya hidup } \\ \text { pencegahan } \\ \text { primer } \\ \text { pencegahan } \\ \text { stroke }\end{array}$

Rijsbergen Penelitian

et al untuk

(2013) menentukan

kemungkinan

faktor risiko,

prognosis,

waktu saja dan

prediktif $(\mathrm{n}=44)$ atau stroke

$(\mathrm{n}=13)$. Peserta

awalnya dihubungi

melalui telepon dan

diwawancarai di

rumah mereka

sendiri.

Sampel sebanyak 56

peserta (28

percobaan; 28

kontrol) adalah

direkrut dari pusat -

pusat kebudayaan

masyarakat dan

kelompok -

kelompok pribadi di

Indonesia

satu gereja di dua

daerah perkotaan di

Provinsi G, Korea

Selatan.

Convenience

sampling

digunakan. Kriteria inklusi adalah (a)

Joint National

Committee (JNC) 7

prehypertension

tahap pertama

(yaitu, sys-

tolic BP 120e 139

$\mathrm{mmHg}$ atau

diastolik BP 80e 89

mmHg) [7], (b)

umur

antara 40 tahun dan 64 tahun, (c) hunian masyarakat, (d) no pembatasan

aktivitas atau gangguan dalam kemampuan tampil sehari-hari

aktivitas hidup dan

(e) tidak

menggunakan obat antihipertensi

Cohort study Sebuah studi kohort prospektif adalah dilakukan di mana pasien dibandingkan dengan non-stroke kontrol pada 3, 6, 12 dan 24 bulan setelah stroke. kesehatan negatif

Penelitian ini adalah yang pertama untuk mengevaluasi keefektifan

sebuah intervensi untuk meningkatkan pengelolaan risiko faktor risiko stroke untuk orang dewasa yang tinggal di masyarakat dengan prehipertensi di Korea oleh menggabungkan strategi berbasis SDT. Hasil penelitian ini adalah berpotensi sangat berguna dan memberikan bukti awal tentang sebuah Intervensi yang efektif dan layak untuk mencegah stroke bagi orang dewasa itu memiliki risiko tinggi terkena stroke akibat kenaikan tekanan darah dibandingkan

dengan orang dewasa yang memiliki tekanan darah optimal.
Studi COMPAS adalah yang pertama

Secara sistematis mengevaluasi SCC pasca stroke secara prospektif desain longitudinal, mengambil berbagai macam subyektif 


\author{
nilai SCC \\ dalam 2 tahun \\ pertama \\ setelah stroke.
}

$\begin{array}{lll}\text { Lennon et } & \text { Untuk } & \text { Systematic } \\ \text { al } & \text { memeriksa review } \\ \text { (2013) } & \text { basis bukti } & \\ & \text { yang } & \\ & \text { mendasari } \\ & \text { program } \\ & \text { pengelolaan } \\ & \text { diri yang } \\ & \text { spesifik untuk } \\ & \text { stroke } \\ & \text { survivor. }\end{array}$

Sekitar 300 pasien direkrut dari stroke unit tiga rumah sakit di Belanda, sedangkan $\quad 300$ kontrol dicari di antara keluarga (pasangan dikecualikan) dan jejaring sosial peserta. Beragam macam

Variabel subyektif dan obyektif dinilai pada keduanya kelompok yang menggunakan wawancara, kuesioner dan penilaian neuropsikologis

Hasil utama termasuk SCC dan gangguan kognitif objektif, sedangkan Hasil sekunder adalah kualitas hidup, pemulihan subjektif

dan kehidupan sehari-hari berfungsi

Studi yang melibatkan orang dewasa dengan diagnosis klinis stroke, yang mengeksplorasi

self-

intervensi pengelolaan,

disertakan. Seleksi studi diverifikasi oleh dua reviewer yang melakukan

penilaian kualitas metodologis secara independen dan ekstraksi data menggunakan alat yang dikembangkan oleh

Akademi Amerika untuk Cerebral variabel

objektif diperhitungkan. Hasil yang didapat bisa digunakan untuk secara akurat menginformasikan pasien dan keluarga mereka, serta untuk mengembangkan intervensi yang dirancang oleh pasien program untuk akhirnya memperbaiki perawatan pasien stroke.
Dua belas dari studi ini dikecualikan; tiga adalah protokol, dan sembilan studi lebih lanjut adalah

dikecualikan karena intervensi yang dieksplorasi tidak dilakukan telah secara eksplisit digambarkan sebagai 'manajemen diri' program. Lima belas penelitian dipilih untuk ditinjau,

melibatkan total 1.233 peserta. Sembilan ada uji coba terkontrol secara acak, dimana lima diantaranya

uji coba terkontrol acak besar (tingkat 1 bukti9 dimana jumlah subyek> 100), dan empat 


$\begin{array}{lll}\text { Palsy } & \text { and } & \text { adalah studi percontohan } \\ \text { Developmental } & & \text { (bukti tingkat II9 dimana } \\ \text { Medicine } & \text { num- } \\ & \text { ber subyek <100) }\end{array}$

Ketrampilan caregiver pada perawatan pasca stroke dinilai dari beberapa faktor antara lain: 1). Membantu memberi makan dan mencegah terjadinya aspirasi, 2). Mencegah terjadinya ulkus dan perawatan luka, 3). Pencegahan pada resiko jatuh, 4). Membantu mobilisasi, 5). Rehabilitasi. Dalam penelitian ini family caregiver memiliki ketrampilan perawatan yang baik pada pasien pasca stroke, sehingga meningkatkan kemampuan untuk melakukan perawatan pada pasien post stroke (Pitthayapong, 2017 ).

Pencegahan stroke berulang dapat dilakukan salah satunya dengan pemberian obat secara teratur yang dipantau oleh family caregiver, kepatuhan pasien post stroke dalam pengobatan sangat berpengaruh dalam pencegahan stroke berulang (Bushnell et al, 2014).

Stroke adalah penyakit yang disebabkan adanya masalah dalam suplai darah ke otak, beberapa obat dan perubahan gaya hidup atau modifikasi gaya hidup dapat digunakan untuk mengurangi resiko stroke berulang. Faktor resiko yang dapat di modifikasi untuk penurunan resiko antara lain Pantau tekanan darah pasien secara teratur, lipid darah, atrial fibrilation, manajemen diabetes dan Indeks masa tubuh ( Lager et al, 2014 )

Makalah ini masih terbatas dalam penelitian yang menitikberatkan pada family caregiver dalam pemberian asuhan kepada pasien post stroke, Dibutuhkan penelitian lebih lanjut untuk mengetahui apa saja yang mempengaruhi terjadinya stroke berulang pada pasien post stroke.

\section{SIMPULAN DAN SARAN}

\section{Simpulan}

Stroke Education Program efektif untuk meningkatkan peran family caregiver dalam modifikasi gaya hidup pasien post stroke.

\section{Saran}

bagi peneliti selanjutnya yaitu diharapkan dapat melakukan penelitian lebih lanjut mengenai efektivitas Stroke Education Program terhadap Peran family caregiver dalam modifikasi gaya hidup pasien post stroke.

\section{DAFTAR PUSTAKA}

S. Pitthayapong et al ( 2017 ) A Community Based Program for Family Caregivers for Post Stroke Survivors in Thailand. Asian Nursing Research11-150e157. http://dx.doi.org/10.1016/j.anr.2017.05.009

Cheril Bushnell et al ( 2014 ) A new model for secondary prevention of stroke : Transition Coaching For Stroke. Perspektif Article doi : 10.3389/fneur.2014.00219

Anne Forster et al ( 2013 ) A structured training programme for caregivers of inpatients after stroke (TRACS): a cluster randomised controlled trial and

Efektivitas Stroke Education Program ( Sep) Terhadap Peran Family Caregiver Dalam Modifikasi Gaya Hidup Pasien Post Stroke: A Literature Review 
cost-eff ectiveness analysis. Lancet Article. http://dx.doi.org/10.1016/S0140-6736(13)61603-7

Theodore Wein et al ( 2017 ) Canadian stroke best practice recommendations: Secondary prevention of stroke, sixth edition practice guidelines, update 2017. International Journal of Stroke0(0) 1-24! 2017 World Stroke Organization Reprints and permissions:sagepub.co.uk/journalsPermissions.nav DOI: $10.1177 / 174749301774306$

Lager KE et al ( 2014 ) Interventions for improving modifiable risk factor control in the secondary prevention of stroke. Cochrane Database of Systematic Reviews 2014, Issue 5. Art. No.: CD009103. DOI: 10.1002/14651858.CD009103.pub2.Lager KE et al ( 2014 ) Interventions for improving modifiable risk factor control in the secondary prevention of stroke (Review).

Jie Gong et al ( 2015 ) Efficacy of a Community-Based Physical Activity Program KM2H2 for Stroke and Heart Attack Prevention among Senior Hypertensive Patients: A Cluster Randomized Controlled Phase-II Trial. PLOS ONE | DOI:10.1371/journal.pone.0139442

Tara L Stewart et al ( 2016 ) Attributing heart attack and stroke to "Old Age": Implications for subsequent health outcomes among older adults. Journal of Health Psychology 2016, Vol. 21(1) 40-49 (C) The Author Reprints and permissions:sagepub.co.uk/journalsPermissions.nav DOI: 10.1177/1359105314521477hpq.sagepub.com

Hee-Young Song ( 2015 ) Effectiveness of a Stroke Risk Self-Management Intervention for Adults with Prehypertension. Asian Nursing Research journal homepage: $\quad$ www.asian-nursingresearch.com http://dx.doi.org/10.1016/j.anr.2015.10.002

Marielle W A van Rijsbergen et al ( 2013 ) The COMPlaints After Stroke (COMPAS) study: protocol for a Dutch cohort study on poststroke subjective cognitive complaints. s. BMJ Open 2013;3 :e003599. doi:10.1136/bmjopen-2013-003599

Sheila Lennon ( 2013 ) Self-management programmes for people post stroke: a systematic review. Clinical Rehabilitation 27(10) 867-878 Reprints and permissions: $\quad$ sagepub.co.uk/journalsPermissions.nav DOI: 10.1177/0269215513481045cre.sagepub.com 